\title{
10 El tráfico transatlántico y más allá
}

En su artículo "Seix Barral y el boom de la nueva narrativa hispanoamericana: las mediaciones culturales de la edición española”, Fabio Espósito observa que

La expansión hacia los mercados hispanoamericanos es una preocupación que domina a libreros y editores españoles desde mediados del siglo XIX cuando, abandonados definitivamente los sueños de reconquista luego de la guerra con Chile y Perú (1865), se consolida el lento camino de la normalización diplomática entre el Reino de España y las nuevas repúblicas, que se había iniciado tenuemente con el Tratado de Paz y Amistad firmado con México en 1836 y finalizaría en 1904 con el reconocimiento de Panamá. Desde entonces América se convierte en un horizonte hacia donde se dirigen con bastante frecuencia los sueños y los anhelos de los autores y editores peninsulares. Pero esa vocación americanista o, mejor dicho, ese afán exportador, no puede explicarse sin atender a las múltiples y variadas relaciones que los editores y libreros españoles establecen con los mercados editoriales del resto de Europa.

Formulado a finales del siglo XIX, este modelo de expansión editorial, que hace hincapié en el carácter mediador de la edición española entre el polo europeo y el americano, permanecerá vigente durante casi todo el siglo XX. Es la clave explicativa de la polémica de los escritores vanguardistas sobre el meridiano intelectual en 1927, el legado que continuarán algunas de las grandes editoriales argentinas y mexicanas a partir de 1938 y uno de los puntos más significativos del programa modernizador de la editorial Seix Barral de Barcelona en la década de 1960.

Como he tratado de argumentar en el apartado anterior, la función mediadora que se autoatribuye la edición española en los años 60, con Seix Barral como editorial abanderada, va a experimentar un nuevo salto modernizador en los años 90, una vez que la Caída del Muro y el quinto centenario de la llegada de los españoles a América inauguraran nuevas condiciones históricas para la producción y puesta en circulación internacional de bienes materiales y simbólicos. Anagrama, por su parte, va a saber aprovechar de manera exitosa la coyuntura y ofrecer un sólido relevo para el lugar que Seix Barral había dejado vacante. He anotado también que uno de las marcas distintivas de Anagrama es saber "colocarse en la confluencia de los tráficos de literatura mundial”, es decir, su extraordinaria capacidad para operar multidireccionalmente: al mismo tiempo que ofrece literatura en castellano y traducida a los mercados del mundo iberoamericano; también provee de literatura redactada, originalmente, en lengua castellana a los mercados de las otras lenguas hegemónicas de Occidente y Oriente. Barcelona, así, se posiciona como nodo de distribución por donde pasan los flujos que circulan desde el mundo hacia América Latina y desde América Latina hacia al mundo. Un tipo de ensamblaje estratégico, que como comenta Espósito, ya había comenzado a delinear Barral: 
La fórmula es ya conocida: entrar a Hispanoamérica con traducciones y autores nativos, aunque ya no con los novelistas franceses de segundo orden y la enorme estela de la poesía modernista, sino con los autores consagrados de la vanguardia europea y las figuras de la nueva narrativa hispanoamericana. Pero ahora se añade un ingrediente, ausente a comienzos del siglo XX. La edición en Barcelona facilita la negociación de los derechos de traducción a otras lenguas europeas y la literatura en lengua castellana se convierte en una prolífica fuente proveedora de éxitos editoriales a escala internacional. El puente ahora es de ida y vuelta.

Esa función de "puente de ida y vuelta" va a ser, precisamente, la que va a asumir de manera efectiva y sustentable Anagrama hasta convertirse en un actor protagónico y decisivo en los tráficos internacionales de literatura. Además, y esto es lo que le da ventaja relativa en relación con la competencia que representan Planeta y las dependencias del grupo Bertelsmann, la editorial de Herralde va a concentrar un importante capital simbólico lo que se va a traducir en una amplia aprobación a sus publicaciones y, en general, a su política editorial por parte de algunos de los sectores más especializados del campo literario, la de cierta crítica y la de ciertos estudios académicos a un lado y otro del Atlántico.

Ya he comentado en el capítulo anterior el premio que otorgan la Editorial Popular de China y la Asociación de Hispanistas, donde Anagrama comparte el privilegio, únicamente con el grupo Planeta y el grupo Bertelsmann, de que títulos propios hayan sido reconocidos. Me interesa en este apartado profundizar en algunos aspectos relativos a las ramificaciones internacionales que se despliegan desde el núcleo operativo establecido en Barcelona. El punto de partida sería que estas ramificaciones no siguen patrones arbitrarios sino que van a estar, al menos de modo parcial, reguladas y controladas a priori por medio de cláusulas establecidas en los contratos de Anagrama y en políticas editoriales concretas, ya sean explícitas o implícitas.

En referencia a Seix Barral y a su proyección internacional como agente mediador entre América Latina y Europa, Espósito ya ha destacado que "El contrato modelo utilizado por Seix Barral otorga al editor la exclusividad para negociar los derechos de traducción de las obras contratadas y el 50\% de los beneficios”. Mediante esta cláusula, Seix Barral asumía la responsabilidad de promocionar la traducción de sus publicaciones a otras lenguas europeas y se reservaba una participación en la ganancia por venta de derechos, con lo cual también quedaba fundado un núcleo de intereses compartidos entre editorial y autor. La política de Anagrama, diseñada para sortear en la medida de lo posible la participación de agentes literarios y, no obstante, mantener el control de los tráficos internacionales, retoma esta pauta y la reinserta en un escenario de carácter netamente global. Entre las normas que regulan la publicación de los textos reconocidos con el Premio Herralde queda establecido que 
4. El autor de la novela ganadora cede a Editorial Anagrama el derecho exclusivo de
explotación de su novela en cualquier forma y en todas sus modalidades, para todo el
mundo. Quedan también reservados en exclusiva a la editorial convocante los derechos de
traducción para la edición en todos los idiomas, por los que el autor recibirá un $80 \%$ de las
cantidades percibidas por la editorial.
(Sitio web Anagrama, "Bases 2018")

Con esta doble pauta, Anagrama garantiza para sí el control de los tráficos en ambas direcciones. Si, por un lado, se reserva el derecho de explotar comercialmente el texto redactado en castellano sin restricciones geográficas, lo que, en concreto, básicamente significa que la editorial va a monopolizar los derechos de edición y distribución en España, América Latina y EE. UU.; por el otro, al reservarse en exclusivo los derechos de traducción, va a establecer un control directo sobre las potenciales traducciones que se realicen del texto en cuestión. Al respecto de este último punto, es de destacar que la editorial va a convertirse en propietaria exclusiva de los derechos de traducción y que, al autor, quien desde el momento de la firma del contrato ya no los posee, le "cede" un $80 \%$ de los beneficios económicos. Me interesa, además, poner de relieve el carácter actualizado del horizonte de acción en el que opera Anagrama: mediante esta cláusula, la editorial fundada por Herralde va a producir textos en castellano "para todo el mundo" y controlar los derechos de traducción a "todos los idiomas”. De aquí en más, una vez establecidos jurídicamente el marco operativo y la distribución de beneficios económicos, la tarea va a consistir en poner en acción la red de actores con competencias territoriales específicas.

Como he comentado en el apartado anterior, hacia 1976 Anagrama se incorpora a un consorcio editorial a escala europea, en principio, para entregar el fallido Premio de los Siete Editores. Las editoriales asociadas en aquel entonces eran Wagenbach (Alemania), Feltrinelli (Italia), Christian Bourgois (Francia), Calder Publishing (Inglaterra), Van Gennep (Holanda) y Dom Quixote (Portugal). De aquel momento, aunque el premio en sí no haya llegado a prosperar, Herralde recuerda los "encuentros, que iniciaron o consolidaron mi amistad con los editores confabulados". Con el tiempo, con base en este incipiente entramado de afinidades, se va articular una sólida red de tráficos literarios y económicos que en particular Herralde va a saber explotar diestramente en función de su programa de producción de literaturas hispánicas para el mundo.

Así, Sergio Pitol, por ejemplo, cuyos derechos de publicación van a ser gestionados directamente por Herralde, para las traducciones al alemán, va a establecer un lazo de fidelidad con Wagenbach y convertirse en uno de los nombres más representativos de su catálogo: hasta el momento se registran seis títulos de su autoría, entre ellos, Defilee der Liebe (2003) (Fig. 4). Como se observa a continuación, la posterior reedición de 2006 por parte de Anagrama, al reproducir 


\section{Sergio Pitol}

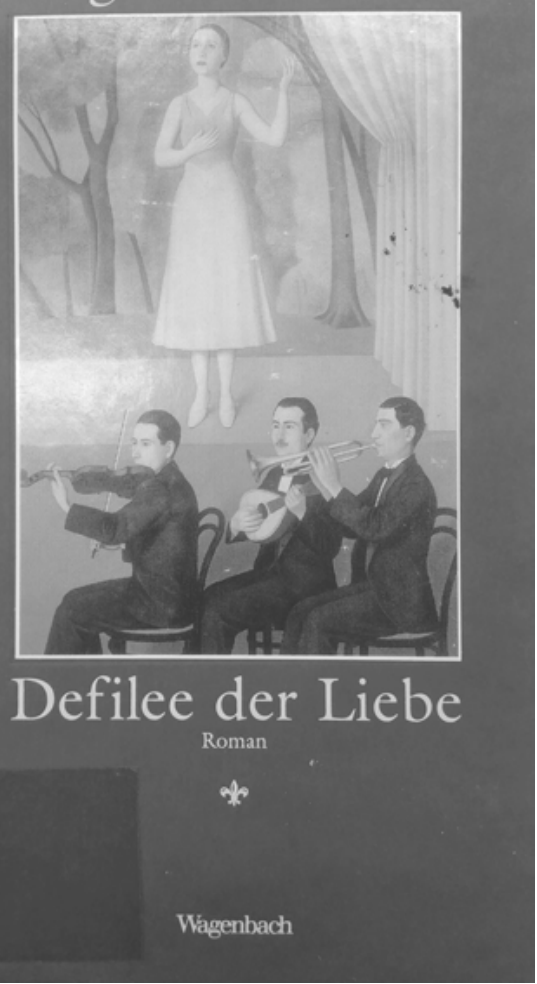

Fig. 4: Portada de la versión alemana de El desfile del amor: Defilee der Liebe (2003) (C Verlag Klaus Wagenbach 2003. Diseño de portada: Birgit Thiel. Ilustración: “Canzone”, Antonio Donghi, 1934).

la misma imagen de portada que posee en Wagenbach, hace explícito el principio mimético para la articulación de proyectos compartidos y el estrecho vínculo que conduce de una editorial a la otra (Fig. 5).

Alan Pauls se mantiene fiel a Anagrama desde el 2003 cuando obtuvo el Premio Herralde con El pasado. En el 2005 Christian Bourgois publicó Le Passé y desde entonces ha ido publicando sus títulos con la misma periodicidad que la editorial de Herralde: en la actualidad la editorial francesa suma siete títulos de su autoría frente a los ocho que se registran en Anagrama. Otras traducciones de El pasado han aparecido en Feltrinelli (2007), al italiano, y en Dom Quixote (2010), al portugués. 


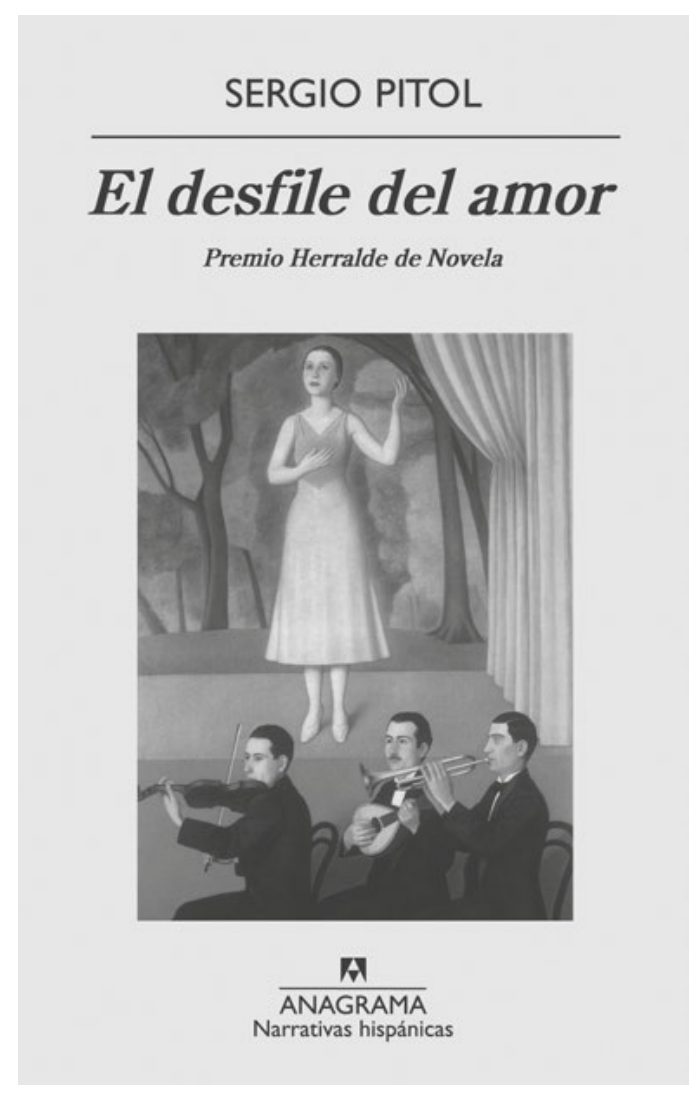

Fig. 5: Portada de la edición de 2006 de El desfile del amor (C Editorial Anagrama 2006. Diseño de colección: Julio Vivas. Ilustración: “Canzone”, Antonio Donghi, 1934).

Leila Guerriero y Alejandro Zambra han entrado más recientemente en la órbita de influencia de Jorge Herralde. De la primera, hasta el momento han aparecido dos títulos en Anagrama: Una historia sencilla (2013) y Zona de obras (2015). El primer título -de los dos, el único publicado en la colección “Narrativas Hispánicas" aunque también es una crónica como las que reúne Zona de obras - fue traducido y publicado, entre otras lenguas, al italiano, por Feltrinelli, y al francés, por Christian Bourgois. De Zambra, los títulos aparecidos en Anagrama son cuatro, todos con un importante número de traducciones, entre ellas, al alemán por parte de Suhrkamp. Roberto Bolaño -hasta tiempos recientes bajo gestión de Herralde y ahora de Andrew Wylie- es el escritor de lengua hispana más publicado por Anagrama y de quién se cuentan más 
traducciones. ${ }^{1}$ En francés ha aparecido regularmente en Christian Bourgois, mientras que en inglés y alemán lo ha hecho en editoriales afines y vinculadas a Anagrama como New Directions y Antje Kunstmann, respectivamente.

A la red de proyección internacional temprana, digamos a la de los siete editores, se han ido sumando otras casas editoriales, en ocasiones desprendidas de las primeras. "Un caso curioso" -comenta Jorge Herralde- es "el de [Juan Pablo] Villalobos. Se lo envié a Berenberg, [...] el que fue asesor literario en español de Wagenbach y después de Antje Kunstmann; empezó hace unos años una pequeña editorial exquisita de no-ficción, le mandé Fiesta en la madriguera y le gustó tanto que decidió empezar una serie de ficción con este libro" ("Jorge Herralde...” 14). De este modo, la red internacional de Herralde se ha ido ramificando de tal suerte que la editorial ahora dispone de un espectro de potenciales opciones para intentar la colocación de sus publicaciones en cada uno de los diferentes mercados europeos. En Italia, por ejemplo, las traducciones de títulos de Anagrama se reparten, principalmente, entre Einaudi, Feltrinelli, Mondadori, Adelphi y Sur. En Alemania, entre Hanser, Wagenbach, Berenberg, Antje Kunstmann y Suhrkamp.

Al momento de mapear el itinerario internacional de las publicaciones de Anagrama, destaca el dato de que los títulos reconocidos con el Premio Herralde de Novela, y con frecuencia también los declarados finalistas, suelen ser traducidos sin mayor dilación por varias casas editoriales europeas afines. Así, por ejemplo, Los Living (2011), de Martín Caparrós, apareció en alemán (Berlin Verlag 2014) y francés (Buchet \& Chastel 2014). Ciencias morales (2007), de Martín Kohan, fue traducida al alemán (Suhrkamp 2010), inglés (Serpent’s Tail 2012), francés (Seuil 2010) y griego (Papyros s. a. -cfr. sitio web Schavelzon-Graham-). Después del invierno (2014), de Gudalupe Nettel, apareció en alemán (Blessing Verlag 2018), francés (Buchet \& Chastel 2016), italiano (Einaudi 2016), noruego (Solum 2018), holandés (Signatuur 2016), inglés (MacLehose Press 2018), y búlgaro (ToniPress 2015). Así, en vistas de este indicador, es posible argumentar que ante todo el premio, pero también la simple inclusión de un título en el catálogo, opera como una importante plataforma para la producción y desarrollo de literatura mundial. Se puede sostener que, desde mediados de los años 90, Anagrama publica, al menos indirectamente, para "el mundo" y no solo para su mercado "natural", que constituiría España. Pero sería desacertado atribuir este fenómeno de propagación de literaturas hispánicas hacia otros territorios

1 En Anagrama aparecieron diecinueve títulos, de los cuales -según datos de la editorial- los más traducidos son, en primer lugar, Nocturno de Chile, veintidós traducciones, Los detectives salvajes, veinte, y Estrella distante, trece. 
lingüísticos al "azar" del mercado o la "suerte" de los libros; antes, habría que poner en foco la decidida política editorial impulsada por Herralde, una que como se observó- comprende tanto la configuración de un marco jurídico favorable como la articulación estratégica del capital social acumulado. Fabio Espósito ha anotado que "Las buenas relaciones de Barral con los editores literarios europeos son fundamentales para la participación española en una red de circulación continental de libros y autores que a todos beneficia” (Espósito). Lo mismo, sin duda, vale para Herralde.

Sin embargo, las observaciones ya realizadas en relación con el premio de la Editorial Popular de China y la Asociación de Hispanistas y un seguimiento más atento de la circulación internacional de títulos de Anagrama permiten sostener que en realidad ya estaría adquiriendo una dimensión transcontinental, tanto en lo que refiere a los flujos que conducen de regreso a América Latina como los que se proyectan hacia Asia. Al ser distinguidos con el premio, La hora azul, de Alonso Cueto, y La enfermedad, de Alberto Barrera Tyszka, fueron traducidos y publicados por la Editorial Popular de China, mientras que Los detectives salvajes y otros títulos de Bolaño, por Horizon en China, Minumsa en Korea y Batch Viet Books en Vietnam. También Sergio Pitol y Juan Pablo Villalobos poseen títulos traducidos a lenguas asiáticas. Sin pretensión de agotar las referencias, un caso que no puede dejar de ser mencionado es el de Alejandro Zambra. De sus libros publicados en Anagrama existen varias traducciones a lenguas asiáticas. Al chino en particular, fueron traducidos los cuatro que hasta el momento registra el catálogo de Herralde; todos aparecieron en la editorial Shanghai 99 que progresivamente se viene perfilando como un emporio desprendido del grupo Bertelsmann. Lo destacable de este caso es que, del extenso corpus producido hasta el momento por Zambra -el cual, además de novelas, incluye poemarios y ensayos en editoriales como Vox, Ediciones Stratis, Quid Ediciones, Excursiones, Contrabando y Eterna Cadencia-, los únicos libros que han tenido la suerte de circular más allá de América Latina y Europa son los publicados por Anagrama.

Este recorrido da cuenta de que Anagrama actúa como un gatekeeper protagónico en lo que atañe a la selección y jerarquización de literaturas latinoamericanas que entrarán en circulación internacional, y, además, de que el horizonte de acción no es exclusivamente europeo, sino que también se proyecta hacia el mundo asiático. En virtud del tejido de afinidades e intereses compartidos ya establecido en Europa, las publicaciones de Anagrama cuentan con buenas posibilidades de ser traducidas a las lenguas occidentales hegemónicas y con dependencias (neo)coloniales: por lo pronto, al francés, al inglés, al alemán, al portugués y al italiano. Pero estas traducciones, a su vez, operan como un aval simbólico que va a favorecer la posterior traducción a lenguas asiáticas. De este modo, al menos indirectamente, Anagrama concentra un 
importante poder de decisión sobre lo que se leerá primero en Europa y luego en Asia como "literatura latinoamericana", lo que, si se considera el caso de Zambra, refiere también a la condición genérica de los textos. Formulado en breve, una conclusión que se extrae de este paneo es que, del material en bruto que en términos ideales ofrece el heterogéneo corpus de literaturas latinoamericanas, Anagrama selecciona, de acuerdo con sus criterios e intereses, un reducido grupo de novelas - casi exclusivamente novelas- para ofrecer al mundo. Esta selección, en detrimento de cualquier otro posible recorte, se va a imponer como "literatura latinoamericana mundial". 2

Como el caso de Zambra, el del emblemático Bolaño -de quien Anagrama solo publicó sus textos en prosa- permite -me interesa insistir en el puntodestacar la exclusión de la poesía del catálogo de Anagrama en tanto corpus que, de algún modo, refleja el carácter siempre restrictivo de la circulación y, finalmente, cómo se configura hoy en día la literatura mundial. Esta exclusión, que termina por convertir a poetas en novelistas y por recortar la literatura latinoamericana exclusivamente como narrativa, se funda en criterios e intereses que exceden a la literatura en sí misma y que son atribuibles a un actor privado que toma decisiones de acuerdo con sus propias necesidades. En respuesta a la pregunta “¿Por qué cree que el género poesía no es redituable?”, Jorge Herralde señaló en una entrevista de 2006 que:

Más que creencia se trata de una constatación casi inexorable, según opinión generalizada. Yo apenas he publicado poesía y si lo he hecho ha sido siempre por alguna razón personal, de amistad con el autor o con el traductor; o bien para añadir algún libro de poesía de un autor al resto de la obra en prosa publicada en Anagrama. Así, Del natural de Sebald, que, por cierto, estuvo muchas semanas en las listas de bestsellers de poesía mientras que las ventas no llegaron a dos mil ejemplares: ergo, la poesía no se vende. Claro que pueden producirse fenómenos con determinados autores (cuya calidad literaria no es siempre deslumbrante), desde Neruda a Joaquín Sabina, pasando por García Lorca, Benedetti, Antonio Gala o Mao Tse-tung, si bien éste tenía la ventaja del lector muy cautivo.

(“Entrevista para 'Perfil'...” 261)

2 En sintonía con mis argumentos, Anadelí Bencomo observa que "Otro condicionante de esta industria del libro en español que en su actual dimensión transatlántica se asemeja a otros mercados literarios globales, tiene que ver con la relación entre el modelo de la narrativa global y el protagonismo del género novelesco como discurso ficcional por antonomasia. La dedicación casi exclusiva de las editoriales a promocionar el género de la novela ha obligado a muchos de los escritores latinoamericanos emergentes a probar suerte dentro de este formato predominante, en detrimento de la robusta tradición que en las letras latinoamericanas tienen otros géneros como el del cuento o la crónica. En consecuencia, se produce una imposición genérica que no siempre logra buenos resultados" (“Geopolíticas...” 44). 
Queda así consignado por qué la poesía, que sin duda es un género altamente presente en la dinámicas culturales y editoriales a nivel local en América Latina voy a retomar el punto en el último capítulo-, suele hoy en día no trascender fronteras nacionales: simplemente porque "no se vende" y, por lo tanto, cabe inferir, resulta incompatible con la dinámica productiva de la literatura mundial. ${ }^{3}$ Con lo términos invertidos, sin embargo, la conclusión también podría ser que la recepción internacional no incluye entre sus hábitos de lectura el consumo de poesía (latinoamericana) porque las editoriales capaces de formar esos hábitos -como ejemplarmente lo es Anagrama- se resisten -por razones naturalmente entendibles- a asumir el riesgo.

Pero la circulación de literatura anagramática posee otra dimensión no menos relevante que ya he adelantado: la puesta en circulación en América Latina y su unificación como mercado, a partir de la monopolización de los derechos de publicación "para todo el mundo", de textos redactados en o traducidos al castellano. Después de un periodo de inestabilidad, las ya comentadas primeras etapas de la editorial en las que de todas maneras América Latina no estaba en el foco de su atención, desde fines de los años 90, Anagrama afianza su presencia en el subcontinente mediante dos recursos: la distribución y la (co) edición local. ${ }^{4}$ Las distribuidoras que actualmente le garantizan cobertura territorial en América Latina -y EE. UU.- y que operan en exclusivo para Anagrama son las siguientes: Riverside Agency (Argentina), Fernández de Castro (Chile), Grupo Penta Distribuidores (Colombia), Spanish Publishers (EE. UU.), Colofón (México), Océano (Panamá, Perú), Desarrollos Culturales Costarricenses (Costa Rica) y Distribuidora Gussi (Uruguay). En lo que refiere a la edición directamente en América Latina, Herralde informa, por un lado, sobre la impresión local de los libros, con lo que se evita el costo de transporte y de aduana y, por lo tanto, el

3 Este criterio de selección "real" -honesto y comprensible- entra en tensión con la frecuente afirmación de Herralde según la cual "El único criterio de valoración seguido [para la asignación de los premios] es la calidad del texto, independientemente de la mayor o menor comercialidad del mismo" ("Introducción..." 21). Si el valor literario en efecto tuviese prioridad como mecanismo de selección, no se podría explicar la exclusión de la poesía ni tampoco, como veremos en el próximo apartado, la de textos experimentales como Tadeys, de Osvaldo Lamborghini.

4 En una conferencia llevada a cabo en Guadalajara en el 2005, Herralde destacó, precisamente, estos dos factores en los siguientes términos: “... ahora Anagrama cuenta con una distribución estable, desde hace años, en muchos países de América Latina y desde luego en los dos mercados más importantes, México y Argentina.

Aparte de dicha estabilidad, basada en distribuidores en exclusiva, desde hace unos pocos años se ha producido un hecho significativo para incorporar a nuestro catálogo, en mayor medida y de forma significativa, a escritores latinoamericanos: las ediciones locales en varios países" ("El editor independiente...” 234). 
encarecimiento de los libros: "empezamos a publicar allá [en Argentina] nuestros libros, cuyo contenido enviábamos por vía electrónica, y que nuestra distribuidora Riverside transformaba en libros prácticamente idénticos, salvo quizá por pequeñas diferencias de calidad del papel, en unos pocos días" ("El editor independiente...” 235). ${ }^{5} \mathrm{Y}$, en segundo, de las coediciones como la de La hora azul: "Aparte de realizar una edición internacional, hemos llegado a un acuerdo con su editorial peruana, Peisa, para una fórmula de coedición en su país” (236).

Así, con base en estas dos estrategias, Herralde garantiza una cierta presencia de su editorial en América Latina, pone en circulación sus publicaciones más allá de su territorio natural -España- y complementario -Europa-, absorbe a las (ex)colonias españolas como mercado unificado por la lengua compartida y, finalmente, produce una suerte de efecto retorno al devolver a América Latina textos de escritores latinoamericanos que han pasado por mecanismos de consagración europeos y, por lo tanto, cargan con un excedente en prestigio.

Este último fenómeno es de capital importancia para iluminar la lógica de la literatura mundial en contraste con las literaturas locales. Independientemente del valor que se le pueda haber asignado previamente en su circuito de origen y si es que se le ha asignado alguno, por efecto de la desterritorialización del prestigio -que ya he comentado siguiendo a James English- un escritor o un texto premiado, o simplemente publicado, en Europa se va a ver revestido de un carácter aurático que va a influir en la valoración que se haga más tarde en regiones periféricas. El reconocimiento de Occidente opera, así, como garantía suficiente para la evaluación positiva de ciertos bienes culturales en todo el mundo. No importa -o nadie se detiene a considerar- que ese reconocimiento que puede ofrecer Occidente, o para el caso la editorial Anagrama de Barcelona, sea uno fundado en intereses económicos privados y en premisas culturales específicas, de tal modo que los textos que Herralde selecciona para incorporar a su catálogo, de manera por completa legítima de acuerdo con sus criterios y en función de la sustentabilidad del proyecto, retornan -y este es el significado más específico que le quiero asignar al término- a América Latina rodeados de un aura que, de ahí en más, no requerirá mayor sometimiento a juicio crítico. Como ejemplo, valga el caso de la recepción de Coronel Lágrimas (2014) en Costa Rica, el país donde creció su autor, Carlos Fonseca, para luego trasladarse a EE.UU. y más tarde a Inglaterra, donde reside actualmente. Una nota publicada por Danny Brenes en el periódico local La Nación da cuenta del significativo valor agregado

5 En referencia a la publicación en España y México de Ese modo que colma (2010), de Daniel Sada, véase Padilla "Independientes". 
que asigna, de por sí, el hecho de que la novela haya sido publicada por Anagrama. Reproduzco el episodio que introduce la nota:

\begin{abstract}
En algún momento del 2014, el teléfono móvil de Carlos Fonseca vibró: acababa de recibir un mensaje por correo electrónico. Fonseca, moreno, de lentes y pelo negro a ras, de risa abundante y palabra certera, se encontraba en un restaurante cenando en soledad.

De pronto, la cena dejó de ser importante. Sin tener con quién compartir la noticia, Carlos cerró el puño en señal de celebración, como lo hace un tenista cuando consigue una anotación complicada. Fonseca acababa de hacer el match point más importante de su carrera literaria.

Con el pecho todavía agitado llegó a su casa, abrazó a su esposa y le contó las buenas nuevas: "Estimado Carlos. Le informo que su novela la leyó un lector inicial y le gustó. Luego la leí yo y la encontré muy sugerente. La leí de nuevo yo, y me siguió gustando. Nos gustaría publicarla”.

El emisor de este mensaje era Jorge Herralde, la legendaria cabeza de Anagrama, una de las casas editoriales más importantes del mundo, quien deseaba agregar Coronel Lágrimas, la novela debut de Fonseca, a su catálogo.

Con ese correo electrónico, Carlos se convirtió en el primer costarricense en ser publicado por la editorial de Barcelona.
\end{abstract}

Como se advierte en el registro encomiástico de este pasaje, que la publicación haya aparecido bajo sello anagramático es razón suficiente para que, en el retorno a Costa Rica, el texto se manifieste rodeado de un aura distintiva. Puesto que la publicación metropolitana se constituye por sí misma como instancia de consagración, la lectura y la evaluación crítica van a devenir innecesarias. Quiero decir -y esto de ninguna manera debe ser considerado una evaluación de Coronel Lágrimas- que, independientemente del valor literario que pueda tener un texto publicado por Anagrama, el hecho de que la editorial lo haya seleccionado para incluirlo en su catálogo alcanza para otorgarle una importante cuota de valor simbólico. Este fenómeno de desterritorialización y automatización de la asignación de prestigio va a contrastar, a su vez, con las limitaciones que va a presentar la publicación local latinoamericana para establecer e imponer sus propias pautas de canonización.

Entre las muchas -y merecidas- distinciones que Jorge Herralde ha recibido por parte de instituciones al otro lado del Atlántico, se encuentra el título de profesor honorario de la Universidad Diego Portales en el 2007. En la ceremonia de reconocimiento, Carlos Peña, presidente del consejo consultivo de la Cátedra Abierta en homenaje a Roberto Bolaño, dijo que "El prestigio de Anagrama y el aura con que él [Herralde], a través de los años, ha sabido proveerla, está [...] presente por aquí y por allá entre el público lector y universitario y ya casi no hay entresijo de la cultura en el que se no se advierta un rastro, siquiera mínimo, de los libros y de los escritores que él ha contribuido a descubrir o a erigir entre nosotros". Acertado en todo, lo que Peña, no obstante, no consigna es que 
Anagrama no deja de ser una empresa privada que, comprensiblemente, prioriza sus necesidades y criterios a la hora de seleccionar qué va a envolver con el influjo de su aura. Tampoco que la asignación de prestigio se realiza en, y en función de, un centro de producción cultural específico dominado por su propia lógica y que, por lo tanto, no (necesariamente) se corresponde con las asignaciones de prestigio locales y heterogéneas a las que, de todas maneras, remite. Por último, no menciona que el proceso de "descubrir" o "erigir" "entre nosotros” se funda en una relación asimétrica de poder, según la cual la metrópoli dispone de esa facultad, mientras que los dominios culturales subordinados tienden a reproducir miméticamente sus prescripciones. En contraste con las editoriales de baja proyección de ventas y escasa cobertura territorial, Anagrama va a constituirse, así, en un agente prestigiador a escala mundial, lo que, curiosamente, también incluye en posición subordinada a América Latina.

En referencia a las dinámicas de las literaturas africanas, Adaobi Tricia Nwaubani anota que

Literary audiences in many African countries also simply sit and wait until the Western critics crown a new writer, and then begin applauding that person. After all, these are the same connoisseurs who brought Chinua Achebe and Wole Soyinka and Ngugi wa Thiong'o to our adoring attention. Local writers without some Western seal of approval are automatically perceived as inferior. In international conversations about African literature, their books receive no mention.

Algo similar, mutatis mutandi, se podría afirmar de lo que aquí nos interesa: que, con frecuencia, las audiencias literarias latinoamericanas "se sientan a esperar" que Herralde, como en su momento lo hacía Barral, consagre a su nuevo escritor “estrella”. Y que, paralelamente, los proyectos locales más sugerentes muchas veces son considerados inferiores o simplemente no son mencionados en los debates sobre literatura latinoamericana. 